\title{
LA FOTOTECA DEL LABORATORIO DE ARTE
}

\author{
POR J. M. SUÁREZ GARMENDIA
}

Se quiere dar a conocer la existencia de un archivo fotográico, patrimonio de la Universidad de Sevilla, cuyos fondos se comienzan a generar en la primera década de este siglo cuando D. Francisco Murillo Herrera viene a fundar el Laboratorio de Arte.

Su contenido es valiosísimo desde el punto de vista de la imagen tanto por la cantidad como por la calidad del mismo, con dos grandes apartados de positivos y de negativos. En él podemos encontrar desde negativos gigantescos con formatos de $30 \times 40 \mathrm{~cm}$. hasta los versátiles de $35 \mathrm{~mm}$. así como diversos soportes, cristal, acetatos, poliéster, celuloide... En cuanto a su valor documental, es fundamentalmente de contenido artístico y arqueológico.

Estos fondos se han formado por encargo exprofeso del Laboratorio de Arte, así como a través de numerosas donaciones. Su estado de conservación es bastante crítico, con diversas patologías que de no corregirse terminarán debilitando la imagen irremisiblemente en un periodo de tiempo relativamente corto. Debido a estas circunstancias su consulta, por ahora, es bastante restringida.

We want the photographic archives, the heritage of the University of Seville, to get widely known. Its contens started in the very early part of 20th century, when professor Murillo Herrera set up the Art Laboratory.

Its materials are most valuable from the point of view of the picture as much as for the quantity and quality of them, with two large sectiones: one for negatives and one for positives. Both large negatives and the smallest ones can be found there, all of them mounted on the most different kinds of holders. As regard its artistic and archaeological value is an vuavoidable step for any historic or restorer study of the artistic legacy in Seville, its province and any other part in Spain. There are also important collections of European and American series.

These funds have been undertaken by the Art Laboratory and many donations have been bestowed. Its state of conservation is quite critical with every sort of pathology and should it not be dealt with at once they will end up ruining the image in a very near future. Due to this, its consultation is very restricted at the moment.

Desde luego no puede decirse que el ámbito cultural español haya valorado la fotografía lo mismo que lo han hecho en otros países de nuestro mismo entorno cultural. Aquí, en muchos casos, nos hemos tomado la libertad de despreciarla no sólo desde el punto de vista estético, sino también desde su otra vertiente; la documental. ¿dónde están si no los archivos fotográficos de nuestras instituciones con 
las imágenes generadas en tiempos pasados? o ¿dónde están los museos de la imagen fotográfica, las publicaciones bibliográficas o los porfolios de nuestros fotógrafos?

La verdad es que hasta hace muy poco tiempo para un amplísimo sector de nuestra sociedad la imagen fotográfica solo les traía connotaciones con aquellas que se realizaron en su primera comunión o en el día de su boda. En fin esta situación parece ser que ha cambiado en la última década y la sensibilización por estos temas parece que está en alza generandose en los últimos años una gran recuperación y restauración de archivos de fotógrafos históricos así como la difusión museística y profusión bibliográfica, traducciones y estudios monográficos.

La ampliación curricular de nuestra universidad con el auge de los estudios sobre comunicación parece que ha dado cabida definitivamente a su estudio dentro del campus universitario. Estos estudios estuvieron siempre relegados a los programas de algunas Escuelas de Artes y Oficios, dándose la circunstancia de que al campo profesional se accedía generalmente desde el amateurismo y en muchos casos desde el mismo autodidactismo lo que produjo sin duda un tremendo retraso que ya denunciara al final de la década de los setenta Manuel de Falces.

Verdaderamente pocos han sido los centros e instituciones que se han dedicado a guardar sistemáticamente en sus fondos la imagen fotográfica de la misma manera que lo han hecho con fondos documentales de otra índole y soporte. De esta forma ahora nos vemos privados de una fuente para la historia contemporánea con el poder referente y connotativo que posee la fotografía. Creo, por obvio, que no debo insistir aquí en el valor de la fotografía como fuente documental histórica. Por otra parte hemos visto exposiciones recientes, así como la labor realizada por la Hemeroteca Municipal con los archivos fotográficos de Serrano, Sánchez del Pando, Gelán y otros, o el empeño puesto por el Instituto del Patrimonio Histórico Andaluz y un largo etc. que lo justifican de manera puntual.

Hago aquí estas reflexiones para poner de manifiesto, aún más si esto es posible, la visión de futuro, la generosidad y la modernidad en su concepción, de aquellas generaciones de profesores e investigadores de Arte que constituyeron e hicieron posible el nacimiento de esa institución universitaria conocida como LABORATORIO DE ARTE, en el seno de lo que fue la Facultad de Filosofía y Letras.

Es de justicia en este punto destacar de forma especial la figura de su fundador D. Francisco Murillo Herrera ', quién en 1907, anejo a su Cátedra de Teoría de la Literatura y de las Artes, va a crear lo que en un principio se denominará Gabinete Fotográfico Artístico. Posteriormente tomó el nombre de Laboratorio de Arte como estrategia ante la Administración para beneficiarse de las ayudas y subvenciones que tenían para sus prácticas de laboratorio las asignaturas de tipo científico que así lo exigían.

1. Una buena aproximación en PALOMERO PÁRAMO, J. M. Prólogo al Tomo I de Fuentes para la Historia del Arte Andaluz. Noticias de Pintura 1700-1720 de Femando Quiles García. Edit. Guadalquivir. Sevilla 1990. 
Precisamente las necesidades derivadas de la docencia y de la investigación de la Historia del Arte y de su concepto experimental y práctico de esta indujeron a Murillo Herrera a iniciar la creación de unos fondos tanto bibliográficos como de imágenes que serán, pasando el tiempo, por un lado la biblioteca departamental de Historia del Arte y por el obro la fototeca del mismo departamento.

Sobre la biblioteca no vamos a hacer ningún comentario aquí, únicamente señalar que durante muchos años ha sido el fondo bibliográfico para la Historia del Arte de obligada referencia para todos los investigadores de esta disciplina y en muchos aspectos sigue siéndolo por la unicidad de buena parte de su contenido.

La fototeca a pesar de la infravaloración y del escaso uso que de ella se ha hecho, debido en parte a la "actualidad" del documento cuando este se generaba, es en estos momentos un paso ineludible en la investigación histórica, un testigo parlante de valor inestimable en cualquier análisis retrospectivo de los temas de sus fondos. Son documentos objetivos a los que hay que recurrir en cualquier revisión de contenido historiográfico artístico que además tienen el valor añadido de estar fechados en su mayor parte. Pero además, salvo raras ocasiones casi siempre por deterioro, de una calidad técnico artística fuera de lo común. Que nadie crea que estoy escribiendo a base de tópicos. Piensen aquellos que saben valorar estos aspectos lo que se puede realizar, a nivel de reproducción gráfica con un negativo de formato $18 \times 24 \mathrm{~cm}$., por poner un ejemplo de los que existen a miles.

El profesor Palomero, apoyandose en el testimonio de algunas personas que conocieron a Murillo Herrera, resume su personalidad destacando, aparte de los valores científicos y personales, su pasión por los libros, la fotografía y el coleccionismo. Esto era público y notorio en la sociedad sevillana de entonces como luego veremos. Pienso que esta pasión quedó proyectada de manera imborrable en la esencia del Laboratorio de Arte. Nos legó, pues con su perseverancia del coleccionista, las mejores herramientas para construir, entre todos los que constituimos la comunidad universitaria, de manera artesanal el entramado histórico de nuestro patrimonio artístico.

Los primeros momentos, como es lógico, debieron ser difíciles y el mismo Murillo Herrera reconocerá que comenzó ilustrando sus conferencias y sus clases sobre arte mostrando postales a sus alumnos. Pero su concepción metodológica de la enseñanza de la Historia del Arte le llevaron a la creación de un banco de imágenes. Así mismo hacia 1918 se planteó como trabajo de investigación el inventario y catálogo de obras de arte existentes en la ciudad y en la provincia ${ }^{2}$ lo que le permitió iniciar de una manera metódica el archivo dándose, de esta manera, la satisfacción de trabajar con un medio tan entrañable para él.

El conocimiento adquirido, a través de sus viajes al extranjero, de archivos dedicados exclusivamente a la comercialización de la reproducción de obras de arte como pudieron ser los italianos Aliniari fundado en 1854 o los franceses A. Braun,

2. Ibid. pág. 24 
fundado en 1862, incluso Jean Laurent en Madrid desde 1870, o el propio Beachy en Sevilla, le hicieron concebir poco a poco la necesidad de crear sus propios fondos. Lógicamente depender de los fondos de los profesionales citados era excesivamente caro aparte de no cumplir su idea de recabar la información de las obras repartidas por todos los pueblos y que no estuvieran en los catálogos de las casas comerciales.

Los primeros años, al menos hasta 1916, los negativos existentes en la fototeca son exclusivamente de Murillo Herrera a excepción de algunas donaciones realizadas por Juan Barrera en 1910 y de Claudio Sanz Arismendi en 1914. A partir de 1917 comienzan las primeras aportaciones de $\mathrm{D}$. Diego Angulo Iñiguez, su discípulo más cercano.

Podemos decir que esta etapa inicial está marcada por la penuria y la escasez, cosa lógica por otra parte si tenemos en cuenta lo novedoso del proyecto, donde aún podían asomarse ciertas dudas sobre su efectividad. Hay que tener en cuenta que solo existía el aval de Murillo Herrera, aquel Catedrático de Teoría de la Literatura y de las Artes, definido por el periodista de El Liberal como "...hombre consagrado al estudio y a la labor educadora del profesor... cuya vida es una linea recta entre el estudio y el deber, de férrea disciplina mental, voluntad potente para la obligación que ha elevado a sacerdocio... su misión educadora de las juventudes que a su cátedra llegan. Su nombre suena en los claustros universitarios españoles y muchos extranjeros donde su labor al frente del Laboratorio de Arte es apreciada en todo su valer..."

Hasta el año 1924 el Laboratorio de Arte estará instalado en torno al segundo patio de la antigua casa profesa de la Compañía de Jesús en la calle Laraña. Un patio recoleto dominado por una altísima palmera y una fuente de mármol, todo de corte muy sevillano. Aquí se reunían los que componían esta empresa universitaria; una familia corta agrupados en torno a Murillo Herrera cuyo fin común, aparte del interés científico y la amistad que les unía, sería acrecentar los dos pilares sobre los que se fundamenta el Laboratorio de Arte: la biblioteca y la fototeca.

Rastreando en los numerosos fondos de la fototeca aún se pueden encontrar algunos negativos que testifican las vivencias y los lugares de estos primeros momentos. Se hacen pruebas de material, máquinas y placas, disparándose sobre modelos de interior, sobretodo mobiliario, objetos, salas, etc. para calcular tiempos de exposición y sensibilidad de las placas. Algunas de estas pruebas han quedado archivadas y hoy constituyen también un testigo de excepción de aquellas precarias y sobrias instalaciones. Otro tanto podríamos decir de personas como bedeles, personal subalterno, catedráticos y alumnos.

En torno a los años 1917 y hasta 1924 se va consolidando la importancia de la fototeca hasta poder afirmar en 1925 que sus fondos pasan de las 18.000 fichas. Posiblemente habría que aclarar que no todas son negativos sino también positivos.

Por estos momentos hemos detectado un incremento de los fondos espectacular, sobre todo a través de donaciones. Muchos de los negativos están firmados por sus autores en el sobre contenedor donde también se incluye la fecha de su realización lo cual es un dato de valor inestimable. A través de estos datos vemos como aquellos 
contribuyentes eran, mayoritariamente, alumnos de Don Francisco Murillo, profesores compañeros y colaboradores en la tarea docente. Salvo las aportaciones de Juan Barraca que sospechamos era fotógrafo profesional, encontramos los nombres de: Francisco de las Barras de Aragón, Salvador Escudero, Francisco Collantes de Terán, Ramón Sánchez Pizjuán, Jiménez Plácer, Díaz del Moral, Pérez de la Concha, Francisco Pagés, Manuel González Santos, Manuel Bago Quintanilla, Francisco Díaz Gely, Enrique Respeto, Angulo Iñiguez, Meyer, Alejandro Guichot, hermanos González Nandín... y otros muchos. Acudieron a la llamada de Murillo Herrera realizada a través de este mensaje en la prensa: "En Sevilla cultivan la fotografía miles de aficionados de todas las clases sociales. Hay amateurs con suficientes medios de fortuna, que en sus viajes obtienen fotografias maravillosas de nuestra riqueza artística. Ellos pueden contribuir a enriquecer los archivos del Laboratorio de Arte enviando copias de estas fotografias, ante las cuales los extranjeros que allí acuden diariamente sabrán apreciar cuan merecido es el renombre de que mundialmente goza nuestro tesoro artístico. Para el Laboratorio de Arte cualquier donativo de esta naturaleza vale mucho más que el dinero...

El texto es elocuente y dibuja con precisión la situación. También nos pone de manifiesto las dificultades que existen para acceder a las subvenciones por parte de las instituciones para este tipo de proyecto. Aceptaban todo lo que sirviera de alguna manera para construir el archivo fotográfico. Así en el apartado de agradecimientos, Murillo Herrera recuerda los donativos de particulares que recibió el Laboratorio destacando una partida de placas fotográficas donadas por el Rector de la Universidad, Don Francisco Pagés, el donativo de 5.000 pesetas hechas por Diego Angulo, hijo del ex presidente del Ateneo, y el realizado por el ex-concejal Don Manuel Bago Quintanilla, consistente en un estante para las diapositivas cuyo valor cifraba en 4.000 pesetas.

Ya en estos primeros momentos señala el profesor la valoración inestimable de sus más estrechos colaboradores en los temas fotográficos: Manuel Bermudo, los hermanos José María y Antonio González Nandín y Enrique Respeto.

Las circunstancias que rodearon la Exposición Iberoamericana de 1929 van a permitir un gran impulso, al menos durante un lustro, a la infraestructura del Laboratorio de Arte. Como complemento de actividades culturales para el magno certamen se había previsto un exposición de arte antiguo que debía instalarse en el pabellón mudéjar de la Plaza de América. En nadie más cualificado que Murillo Herrera podía recaer el papel de comisario y en 1923 Don Fernando Barón, Conde de Colombí y Comisario Regio de la Exposición Iberoamericana, solicita de éste que se encargue del proyecto. El Conde de Colombí, conocedor de la labor de Murillo Herrera, y habiendo valorado su importancia, decide apoyar de alguna manera y canalizar estos esfuerzos a través de la creación de un patronato a cargo del comité de la exposición "para que pudiera dotar espléndidamente al Laboratorio para que éste pudiese cumplir la misión que tiene asignada" Como primera medida y para mayor comodidad son trasladadas al pabellón mudéjar o Palacio de Arte Antiguo, como también se le conoce, el Laboratorio de Arte con todas sus instalaciones. Aquí 
estará ubicada la fototeca y su laboratorio fotográfico hasta el año 1929 en que regresan de nuevo a su antigua casa de la calle Laraña. De este momento hay un trabajo considerable. No obstante la nómina de fotógrafos se reduce habiéndose encontrado negativos firmados por Murillo Herrera, Juan Barrera, Diego Angulo, Diego López, Enrique Marco Dorta, Rafael Salas, pero, sobre todo, de los hermanos González Nandín.

Esta etapa es crucial en la formación de la fototeca. De las palabras del periodista de $E l$ Liberal se desprende que en estos momentos nadan en la abundancia al hacer referencia al Laboratorio de Arte de la Facultad de Filosofía y Letras "regiamente instalado hoy merced al rasgo cada día más plausible del Comité de la Exposición en el Palacio de Arte Antiguo de la Plaza de América".

Pero también de los hechos se desprende la actividad que se desarrolla en estos momentos. No podemos realizar aquí una catalogación de las publicaciones sobre historia del arte que han hecho uso de los fondos del laboratorio. Esto sería interminable y merecedor de una investigación más profunda, pero sí nos gustaría poner de relieve algunas series de negativos realizados exprofeso con el ánimo exclusivo de la documentación y difusión de nuestro patrimonio histórico artístico. No podemos olvidar que la fototeca es eminentemente un fondo documental que, por una serie de circunstancias ahora cobra un valor inestimable pero que además reúne el valor objetivo de ser testigo de un momento de la obra en un tiempo determinado con todas sus circunstancias de conservación. Esto en cualquier caso es el primer punto de partida para cualquier valoración técnica o formal a la hora de acometer una restauración, inventario, estudio histórico o simplemente cualquier revisión historiográfica. Asimismo es prueba irrefutable de la existencia de objetos desaparecidos, destruídos, exportados o añadidos en otros contextos.

Van a ser los hermanos González Nandín y Diego Angulo los que, dirigidos por Murillo Herrera, inicien unas campañas sistemáticas en formatos gigantescos de placas de cristal de 30 x 40 y que posteriormente continuó también Antonio Sancho Corbacho. De estos negativos destacaríamos en primer lugar aquellos que luego se emplearían para la publicación fascicular de la Escultura Andaluza, dirigida por Diego Angulo y publicada en 1927, obra con un planteamiento documental gráfico sin precedentes. El tamaño gigantesco del formato empleado iba a permitir trasladar los negativos a los fotolitos por contacto. En este sentido hay que decir que el sistema de positivado que tenía nuestro archivo siempre era por contacto ya que no había ampliadoras y muchos menos para estos tamaños. Esta circunstancia obligaba a ser muy exigente con la calidad, característica que no se le escapa a ningún profano cuando contempla una placa de este tipo.

También en 'estos años, próximos a la Exposición, se realizan las series dedicadas a las vidrieras de la catedral hispalense en el formato de $30 \times 40$. Se iniciaron los trabajos fotográficos en 1928 como complemento a la labor de restauración que se inicia en los vitrales a propuesta del arquitecto Javier de Luque ${ }^{3}$. Estos trabajos fueron

3. LUQUE, Javier de: Las vidrieras artísticas de la Catedral de Sevilla. Sevilla, 1927. 
revisados por una comisión de expertos de la que formaba parte Murillo Herrera y sirvieron para testificar el estado en que se encontraban antes y después de la restauración. También acudió para recoger esta documentación el Arxiu Mas de Barcelona como continuación de las campañas que había iniciado en las catedrales de Toledo y de Santiago de Compostela por iniciativa de varias instituciones americanas.

La importancia de los estudios hispano-americanos se había puesto de manifiesto a través de esa reacción que se produce con motivo de la exposición de 1929 y a partir de este acontecimiento se crea la cátedra de Historia del Arte Hispano-Colonial. En 1930 es designado como titular de dicha cátedra Don Diego Angulo Iñiguez quien en honor a su cargo se lanza a un trabajo de investigación en el Archivo de Indias que va a culminar con otra magna publicación: Planos de Monumentos Arquitectónicos de América y Filipinas existentes en el Archivo de Indias publicada por el Laboratorio de Arte en 1939. Esta obra, que dio a luz una copiosísima documentación, generó, a su vez, una importante campaña fotográfica en torno a 105 planos existentes en el citado archivo, negativos que se custodian en la serie de América de nuestra fototeca. Aunque la fecha de publicación es en 1939 la obra gráfica se inicia en 1930 y en 1934 sale el tomo III de dichos planos. Poco después Angulo, con la ayuda del Centro de Estudios de Historia de América y de la Junta de Relaciones Culturales, realiza un viaje por Méjico, fundamentalmente, donde, además de cotejar los planos con los monumentos, realiza un recopilación de más de 5.000 fotografías que suponemos son las que se hallan a su vez fotografiadas por Sancho Corbacho en formato de $9 \times 12$.

Por estos años los fondos se van incrementando con rapidez gracias a la incansable actividad de los hermanos González Nandín que hacen de la fotografía su verdadero quehacer diario, un quehacer desinteresado y generoso que ejercieron de forma gratuita ya que su posición social se lo permitía. A esta actividad también se incorporó Rafael Salas, canónigo de la catedral que trabajó mucho en el Archivo de Indias y que allanó, suponemos, las dificultades para fotografiar y conseguir esas series magníficas del patrimonio eclesiástico como son las dedicadas a los libros corales, a las casullas, capas y bordados ${ }^{4}$, a la orfebrería, rejería y un largo etcétera. También inició su labor por estos años Don Antonio Sancho Corbacho, al menos los registros más antiguos que hemos visto firmados por él son de 1932. Podríamos decir, sin temor a equivocarnos, que fue a lo largo de su vinculación al Laboratorio de Arte como profesor adjunto el hombre que más tiempo dedicó a la fototeca. No sólo hizo numerosos negativos y gran parte de los positivos sino que a él se debe la nueva ordenación catalográfica de los negativos así como el diseño de la triple ficha que cada registro posee. Su obra se puede seguir perfectamente año por año ya que su letra y su firma aparecen en miles de fichas y en los contenedores de cada negativo.

Durante la guerra civil y en los años inmediatos se registraron fotográficamente aquellos edificios eclesiásticos que sufrieron las consecuencias de tan lamentable

4. TURMO, Isabel. Bordados y Bordadores Sevillanos. (Siglos XVI a XVIII). Laboratorio de Arte. Universidad de Sevilla. 1995. 
estupidez para enfatizar aún más la situación. Estas fotografías ilustraron dos trabajos de Hernández Díaz y de Sancho Corbacho ${ }^{5}$ que fueron una especie de acta notarial del calamitoso estado en el que quedaron las iglesias y conventos después de haber sido incendiados y saqueados.

Al terminar la guerra civil el archivo fotográfico tenía unos fondos muy considerables lo que en cierta medida hizo posible abordar esa obra gigantesca e inconclusa que fue el Catálogo Arqueológico y Artístico de la Provincia de Sevilla. No obstante esta obra generó una cantidad de negativos impresionante, no solamente aquellos que se publicaron en los cuatro tomos que salieron entre los años 1940 y 1945 sino otros que se hicieron y luego no convino su publicación. Aunque el último pueblo aparecido en el catálogo, siguiendo la secuencia alfabética, es Huervar parece ser que los trabajos estaban terminados, al menos desde el punto de vista gráfico, hasta la letra $\mathrm{O}$. Este encargo, patrocinado por la Diputación Provincial, puso a disposición de los autores todos los medios necesarios lo que permitió un enorme acopio de material que se integro en los fondos fotográficos del Laboratorio de Arte y hoy constituye gran parte de los negativos que se pueden consultar en su epígrafe topográfico.

Los fotógrafos que realizaron esta labor fueron los hermanos González Nandín ayudados en ocasiones por Sancho Corbacho que también intervenía en la parte histórica en el estudio de las artes industriales. En el diseño del catálogo se habían previsto también, como complemento a las fotografías, ilustraciones con dibujos, sobre todo arquitectónicos, como plantas, alzados, planos urbanísticos, etc., lo que motivó incluir en el equipo al aparejador de la Diputación Moreno de Felipe que realizó unos levantamientos magníficos de los edificios estudiados así como una serie de los edificios civiles y religiosos de Sevilla capital. Esta labor posteriormente fue continuada por los delineantes José Fagundo Ginés y José Esteve Guerrero cuyo material pasó a engrosar los fondos gráficos del Laboratorio constituyendo la base de la planoteca del mismo.

A raíz de esta obra Sancho Corbacho salió fortalecido culturalmente de manera que pudo abordar otros trabajos cuya visión global nadie poseía en esos momentos como él. De entre ellos vamos a destacar fundamentalmente aquellos cuya aportación gráfica constituye un tanto por ciento considerable como fueron su tesis doctoral sobre la Arquitectura Barroca Sevillana con más de 700 fotografías y 120 dibujos planimétricos, la Cerámica Andaluza, publicada en 1948 o la magnífica selección de dibujos, estampas y pinturas que realizó para ilustrar la Iconografía de Sevilla publicada en 1975.

Por supuesto que profesores como Don José Hernández Díaz o Don Enrique Marco contribuyeron al engrandecimiento de los fondos fotográficos con encargos para sus numerosísimas publicaciones que luego se integraban en el Laboratorio pero que no comentaremos por no ser series tan numerosas como las anteriormente citadas.

5. HERNÁNDEZ DÍAZ, J. y SANCHO CORBACHO, A. Edificios religiosos y destruidos por los marxistas en los pueblos de la provincia de Sevilla. Sevilla 1937 
Hasta 1973, fecha en que se registra el último negativo de la fototeca, se incorporan trabajos de Rafael Salas, Tomas Molnia, Raimundo Albarrán, Sancho Corbacho, Enrique Marco Dorta, Moreno, Palau y Bustamante.

Otra sección importante de la fototeca es la colección de positivos. Aquí se reúnen decenas de millares de fotografías en muy diversos soportes, técnicas y formatos. El grueso lo constituyen fotografías propiamente es decir imágenes formadas por oxidación de los halogenuros de plata tras la exposición a la luz. Pero como es una colección eminentemente iconográfica hay también otras realizadas por los sistemas fotomecánicos más variados, desde fotografías de prensa, sobretodo de revistas extranjeras especializadas, hasta tarjetas postales, incluyendo dibujos y grabados.

La gran mayoría de este fondo está montado sobre una ficha catalográfica bastante completa donde figura su identificación y todos los datos historiográficos que se pudieron apuntar en el momento de su confección. Lamentablemente hay otras muchas que no contienen ningún dato por lo que sería preciso acometer un arduo trabajo de documentación que enriquecería ampliamente este fondo.

En principio hay que señalar que están ordenadas de forma temática y que no existe un archivo que contabilice estos temas. Únicamente poseemos como orientación los tejuelos de los lomos de los contenedores. En el interior de éstos y en carpetas se suelen agrupar por orden cronológico o geográfico según convenga. Como se puede comprender nos podemos encontrar con muchas sorpresas debido a la subjetividad de los criterios, por lo que de momento la consulta de estos positivos resulta poco operativa.

La procedencia de estos fondos es variada, los más antiguos proceden, con toda seguridad, de donaciones efectuadas por aquellos discípulos y compañeros docentes de Murillo Herrera que conocían la necesidad y la importancia de estas imágenes para la enseñanza, sobre todo en unos momentos en que la proyección de diapositivas no estaba normalizada y los formatos eran gigantescos. El mismo Murillo Herrera nos habla de las compras realizadas en sus viajes por Europa. En fin, suponemos que este material sería de muy diversa procedencia.

Otro componente importante lo constituyen todas aquellas fotografías que resultan de la positivación de los fondos de negativos del propio Laboratorio de Arte. Éstas son fácilmente reconocibles porque al dorso, impreso en sello de caucho, tiene las referencias propias para poder encontrar, a través del registro general; el negativo de la misma. Muchas de ellas están reunidas en carpetas anilladas agrupadas temáticamente formando una colección que, en algún momento, se utilizó como imagen de estudio. Aquí se encuentran también, en estas carpetas, muchas fotografías procedentes del Arxiu Mas de Barcelona con el que debió de existir algún convenio de intercambio.

Una donación voluminosa y cualitativamente importante fue realizada por S.S. A.A. R.R. Don Carlos de Borbón y Doña María Luisa de Orleans. Está compuesta por varios cientos de fotografías de lo que debió de ser un archivo de recuerdos de los innumerables viajes realizados por la familia regia, sobre todo por Europa. Muchas de ellas pertenecieron a los Duques de Montpensier, por lo que abundan 
fotografías del siglo XIX. Sobre todo la componen reproducciones de pintura, escultura, grabado, litografías, dibujos, artes aplicadas, interiorismo, desastres, fotos testimoniales, arquitectura y aspectos urbanísticos de diferentes ciudades europeas como España, Portugal, Italia, Inglaterra, Francia, Alemania, Suiza... Casi todas están montadas en cartón con los anagramas y razones sociales de los fotógrafos, algunos de los cuales muy conocidos.

También es destacable el donativo realizado por los herederos de José Sebastián Barandián ya que aparte de los aspectos personales aportan una visión interesante de la vida de la ciudad.

En este heterogéneo conjunto podemos encontrar fotografías antiguas de ciudades de España y de Sevilla en particular de fotógrafos como Laurent, Beauchi, Garzón, Kaulak, Almela... pero además tiene la particularidad de reunir diversos soportes y técnicas fotográficas. También podemos encontrar muchas series de las casas comerciales extranjeras como Allinari y A. Braum.

El estado de conservación no es demasiado bueno y, sobre todo, es bastante crítico en el caso de los negativos. En la fotografía los elementos materiales que la constituyen, como soportes y emulsiones, son poco estables y en cualquier caso, siempre que no estén convenientemente embasados y en un ambiente de humedad y temperatura determinados, el deterioro es progresivo y constante, sin concesiones de ningún tipo.

Los componentes orgánicos de las emulsiones son un caldo de cultivo inmejorable para concentrar en ellas todo tipo de hongos y bacterias, aparte de otras patologías que no se pueden determinar sin realizar un análisis mucho más profundo. Por otra parte la delicadeza de estas emulsiones y la fragilidad de los soportes con un porcentaje muy elevado de cristal las hacen muy vulnerables a accidentes de todo tipo.

La antigüedad de este archivo, entre 30 y 80 años aproximadamente, ha contribuido a que muchos de los negativos sufran un proceso de metalización o sulfuración de la plata de las emulsiones que, en el mejor de los casos, hace perder transparencia. Al ser un fenómeno que se inicia en los bordes para avanzar hacia el centro, crea zonas de diferentes densidades. También hay algunas cajas de negativos afectados por un proceso de separación de la gelatina del soporte, probablemente por haber sufrido un mal procesamiento, que será muy difícil de remediar.

Otro problema a solucionar con urgencia es el contenedor. Todos los negativos están envasados individualmente en sobre con los datos del negativo escritos sobre éstos y cada decena de negativos colocados en cajas de cartón todo ello realizado de forma meticulosa. Pero el PH del papel no es el apropiado y la higroscopicidad del mismo junto con la goma arábiga de los cierres y la tinta de las rotulaciones han hecho auténticos estragos al transferirse a los propios negativos.

Pienso, no obstante, que con un tratamiento individual con los sistemas que hoy se conocen, incluso con la duplicación y transferencia a un soporte magnético salvaríamos un importantísimo legado cultural, un riquísimo patrimonio del que somos responsables ante las futuras generaciones. 


\section{CONTENIDO DEL ARCHIVO DE NEGATIVOS}

La ordenación de los negativos se realiza de forma práctica por formatos, estando mezclados los soportes. Este dato por lo tanto es importante como punto de partida para la localización del negativo puesto que cada formato tiene un registro independiente de manera que si hay seis formatos distintos podemos tropezarnos con seis números de registro iguales. El número de registro se iba dando conforme se incorporaba el negativo a la fototeca, en este momento también se abría una triple ficha catalográfica con los datos propios como título, localización, formato, autor, fecha, etc... y cada ficha iba a engrosar un fichero independiente: el general, realizado con un criterio topografico, el de conceptos o temático y el registro general. En un paso posterior se incluía dicho negativo en el sobre con los mismos datos que la ficha y pasaba al contenedor que, sin excepción, contiene diez negativos. De esta manera también se pone en relación con el registro general. Así el negativo cuyo registro general sea el número 2.427 estará en la caja 243 del correspondiente formato que contendrá del 2.421 al 2.430. La ordenación, por lo tanto, es de la más eficiente sobre todo a la hora de devolver cada negativo, una vez utilizado, a su caja contenedor.

El formato $30 \times 40$ contiene 329 registros. Se inicia el 15 de enero de 1925, curiosamente cuando González Nandín deja de trabajar en 24 x 30 lo que nos hace suponer que éste es el momento de la adquisición de una nueva cámara. Se inicia con un reportaje de San Isidoro del Campo y de algunas capillas de la catedral con obras de Martínez Montañés y a continuación se comienza una serie muy importante de 234 negativos dedicados exclusivamente a las vidrieras de la catedral que concluye, aproximadamente, en 1930. Esta serie la continúa Sancho Corbacho durante 1932 con 21 negativos más de detalles. En este mismo tamaño se sigue trabajando pero con las restricciones propias del gigantismo del formato que lo hace poco viable y de una aparatosidad extrema. El formato se siguió utilizando durante la guerra en los años 1936, 37 y 38, pero sólo se hicieron unos negativos de escultura y pintura. El último está firmado por Moreno el 3 de junio de 1949 con la pintura del techo de la Compañía Sevillana de Electricidad.

El formato $24 \times 30$ contiene 653 registros, casi todos dedicados a los edificios emblemáticos de la ciudad más un buen reportaje de San Isidoro del Campo del año 1924. La mayoría son de los hermanos González Nandín que hacen del 1 al 498 siendo el primero del 18 de marzo de 1922 trabajando sistemáticamente hasta el año 32. A partir del registro 499 y hasta el 556 están dedicados a una serie de la Capilla de la Universidad que hace Sancho Corbacho y a partir del año 1948 Moreno termina hasta el registro 653 con una serie que contiene el Alcázar, el Museo de Pinturas y la Casa de Pilatos.

El formato $18 \times 24$ contiene 7.715 registros. Los temas de este son muy variados pero, sobre todo, escultura, pintura y arquitectura monumental de la ciudad. Trabajan con él desde el principio Don Francisco Murillo y los hermanos González Nandín, sobre todo antes de la Exposición del 29 y luego Sancho, Salas, Moreno y otros. 
El formato $13 \times 18$, con 15.462 registros, es el de mayor contenido de la fototeca. Desde el punto de vista técnico este dato ya nos da una aproximación sobre la importancia de este archivo. Es un formato profesional que se adoptó como el más idóneo para positivar por contacto y pasarlo a los fotolitos directamente para las publicaciones. Aquí encontramos series muy importantes pero sobre todo las realizadas por los hermanos González Nandín para el Catálogo Arqueológico Artístico de la Provincia, donde estaban recogidas las fotografías de muchos más pueblos de los que se publicaron. Otras series importantes son las de la Catedral, conventos, edificios civiles, etc... En este formato se realizaron también aquellas series que al final de los años 40 inicia Moreno y después en las décadas siguientes continúan Palau y Bustamante con la intención de recoger ese patrimonio de la arquitectura urbana que se estaba perdiendo de forma irremisible en la continua transformación de la ciudad. Es una serie ordenada alfabéticamente por calles donde aparecen numerosos edificios con sus componentes mas singulares. Se recogen no solo los aspectos arquitectónicos sino también otros decorativos como molduras, rejas, cerámicas, interiores... y otros etnográficos de gran interés. A esta serie se agregan todas los realizados con anterioridad por diferentes motivos constituyendo en conjunto un repertorio de aspectos urbanos de la ciudad notabilísimo.

El formato $9 \times 12$ contiene 8.799 registros. No es en su totalidad un $9 \times 12$, sino que abarca otros menores, pero mayores que el paso universal. Hay, lógicamente, una variedad que engloba casi todos los formatos históricos de tipo medio desde el 4 x 4; $6 \times 4,5 ; 6 \times 6 ; 6 \times 9 ; 9 \times 12$ y otros que estuvieron normalizados en su momento.

Indudablemente estos formatos medios fueron los preferidos por su versatilidad, para utilizarlos en los viajes hasta la llegada y estandarización del 24 x $36 \mathrm{~mm}$. o paso universal. Esta circunstancia, por tanto, va a marcar el contenido de los negativos de esta serie. Casi todos ellos o la mayoría son aquellas series que documentan, pueblos, ciudades, etc. en definitiva obras repartidas a lo largo de la geografía nacional y extranjera. Ello no es óbice para que en este formato se documenten muchos de los edificios de la ciudad. Su contenido es variadísimo y no podemos sistematizarlo de una manera breve, pero si hemos constatado que en el mismo están contenidos los varios miles que componen la serie de América, en gran parte realizada por Sancho Corbacho y Angulo (clasificada por orden alfabético).

Por último el formato $24 \times 36 \mathrm{~mm}$. Este formato no está incluido en el registro general aunque si está referenciado en las fichas del archivo con el nombre de MICRO. Están los negativos incluidos en 125 contenedores de 40 fotogramas con una media aproximadamente de unos 30 por contenedor por lo que estimamos un total de 3.600. Su contenido es muy variado donde se encuentran muchos documentos de los pueblos de la provincia así como otro conjunto dedicado a reproducciones de libros con la finalidad de servir para confeccionar diapositivas. 


\title{
EPÍGRAFES DEL FICHERO DE NEGATIVOS
}

\author{
1. Topográfico \\ 1.1. Pueblos de Sevilla \\ 1.2. Pueblos de Andalucía \\ 1.3. Pueblos de España
}

2. Sevilla. Monumentos religiosos.

2.1. Conventos

2.1.1 Ángel Custodio (c/ Rioja)

2.1.2 Asunción

2.1.3 Buen Suceso

2.1.4 Capuchinos

2.1.5 Carmen

2.1.6 Cartuja (Santa María de las Cuevas)

2.1.7 Concepcionistas

2.1.8 Descalzos

2.1.9 Encarnación

2.1.10 Espíritu Santo

2.1.11 Jesús (c/ Cervantes)

2.1.12 Madre de Dios

2.1.13 Mercedarias

2.1.14 Mínimas

2.1.15 Pópulo

2.1.16 María de los Reyes, Santa

2.1.17 Salesas, de las

2.1.18 San Acasio

2.1.19 San Agustín

2.1.20 San Alberto

2.1.21 San Antonio de Padua

2.1.22 San Buenaventura

2.1.23 San Clemente

2.1.24 San Jacinto

2.1.25 San Jerónimo de Bellavista

2.1.26 San José

2.1.27 San Leandro

2.1.28 San Pablo (ver La Magdalena)

2.1.29 Santa Ana

2.1.30 Santa Clara

2.1.31 Santa Inés

2.1.32 Santa Isabel

2.1.33 Santa María de las Cuevas 
2.1.34 Santa María de Jesús

2.1.35 Santa María la Real

2.1.36 Santa Paula

2.1.37 Santa Rosalía

2.1.38 Santo Tomás

2.1.39 Socorro, Convento del

2.1.40 Terceros, de los

2.1.41 Teresas, de las

2.1.42 Trinidad, de la

2.1.43 Valle, del

2.2. Capillas, Colegios y Hospitales

2.2.1 Angeles, Capilla de los

2.2.2 Carmen, Capilla del

2.2.3 Carretería, Capilla de la

2.2.4 Concepción, Capilla de la

2.2.5 Humeros, Capilla de los

2.2.6 Jesús, Capilla de

2.2.7 Montserrat, Capilla de

2.2.8 Montensión, Capilla de

2.2.9 Museo, Capilla del

2.2.10 Patrocinio, Capilla del

2.2.11 San Andrés

2.2.12 San Gregorio, Capilla de

2.2.13 Escolapios (Capilla de los Terceros)

2.2.14 San Gregorio, Colegio de

2.2.15 San Hermenegildo, Colegio y Capilla de

2.2.16 Residencia de los RRPP Jesuitas

2.2.17 San Juan de Dios, Hospital

2.2.18 Venerables, Hospital de los

2.2.19 San Luis, Hospicio de

2.2.20 San José, Capilla de

2.2.21 San Onofre, Capilla de

2.3. Procesiones

2.4. Parroquias

2.4.1 Concepción

2.4.2 Magdalena

2.4.3 Nuestra Señora de la O

2.4.4 Del Sagrario

2.4.5 Del Salvador 
2.4.6 San Andrés

2.4.7 San Antonio Abad

2.4.8 San Bartolomé

2.4.9 San Benito de Calatrava

2.4.10 San Bernardo

2.4.11 San Esteban

2.4.12 San Gil

2.4.13 San Gonzalo

2.4.14 San Ildefonso

2.4.15 San Isidoro

2.4.16 San Juan de la Palma

2.4.17 San Julián

2.4.18 San Lorenzo

2.4.19 San Marcos

2.4.20 San Martín

2.4.21 San Miguel

2.4.22 San Nicolás

2.4.23 San Pedro

2.4.24 San Román

2.4.25 San Roque

2.4.26 San Sebastián

2.4.27 San Vicente

2.4.28 Santa Ana

2.4.29 Santa Catalina

2.4.30 Santa Cruz

2.4.31 Santa Lucía

2.4.32 Santa María la Blanca

2.4.33 Santa Marina

2.4.34 Santiago

3. Archivos

3.1. de Indias

3.2. de Protocolos

3.3. Biblioteca Colombina

3.4. Comisión de Monumentos

4. Museos

4.1. Arqueol6gico Municipal

4.2. Arqueologico Provincial

4.3. Provincial de Pinturas 
5. Universidad

5.1. Biblioteca Provincial

5.2. Capilla de la Anunciación

5.3. Edificio (actual Bellas Artes)

5.4. Facultad de Ciencias

5.5. Facultad de Letras

5.6. Marcas de Impresores

5.7. Junta de Cultura Histórica y Tesoro Artístico

5.8. Laboratorio de Arte

6. Catedral

6.1. Libros de Coro

6.2. Libretos

6.3. Varios (Por orden alfabético)

Arquitectura, Pintura, Escultura, Documentos; Metalistería...

6.4. Capillas

6.4.1 Alabastros

6.4.2 Antigua

6.4.3 Doncellas

6.4.4 Evangelistas

6.4.5 Mariscal

6.4.6 Marmolejos

6.4.7 Piedad

6.4.8 Mayor

6.4.9 Real

6.4.10 San Hermenegildo

6.4.11 San Pedro

6.4.12 Coro

6.5. Orfebrería

6.6. Ornamentos

6.7. Sacristías

6.8. Sala Antecabildo 


\subsection{Sala Capitular}

6.10. Giralda

\subsection{Vidrieras}

7. Edificios Civiles

7.1. Vistas de Sevilla

7.2. Academia de Medicina (antiguo Colegio de San Gregorio)

7.3. Aduana

7.4. Alcázar

7.5. Almacenes del Rey

7.6. Asilo de San Fernando

7.7. Asilo de Mendicidad

7.8. Atarazanas

7.9. Audiencia

7.10. Ayuntamiento

7.11. Caños de Carmona

7.12. Casa Cuna

7.13. Casa del Marqués de Palomares

7.14. Casa del Marqués de Dos Hermanas

7.15. Casa de Miguel de Mañara

7.16. Casa de la Moneda

7.17. Casa de Pilatos

7.18. Casa de los Pinelo

7.19. Cementerio

7.20. Colegio de San Hermenegildo

7.21. Colegio de San Miguel

7.22. Corral de Esquivel

7.23. Diputación

7.24. Dispensario Antitubercoloso

7.25. Cruz Roja

7.26. Escuela Superior de Bellas Artes

7.27. Escuela de Medicina

7.28. Estación de Córdoba

7.29. Palacio Arzobispal

7.30. Palacio de las Dueñas

7.31. Palacio de los Marqueses de la Algaba

8. Exposición Iberoamericana

8.1. Pabellón del Aceite 
8.2. Pabellón de Castilla

8.3. Pabellón de Córdoba

8.4. Casino de la Exposición

9. Colecciones Particulares

Varios (orden alfabético)

10. Artistas Contemporáneos

Varios (orden alfabético)

\section{América \\ Colección Alfabética}

12. Callejero de Sevilla

Vistas urbanas y caserío

Colección Alfabética 


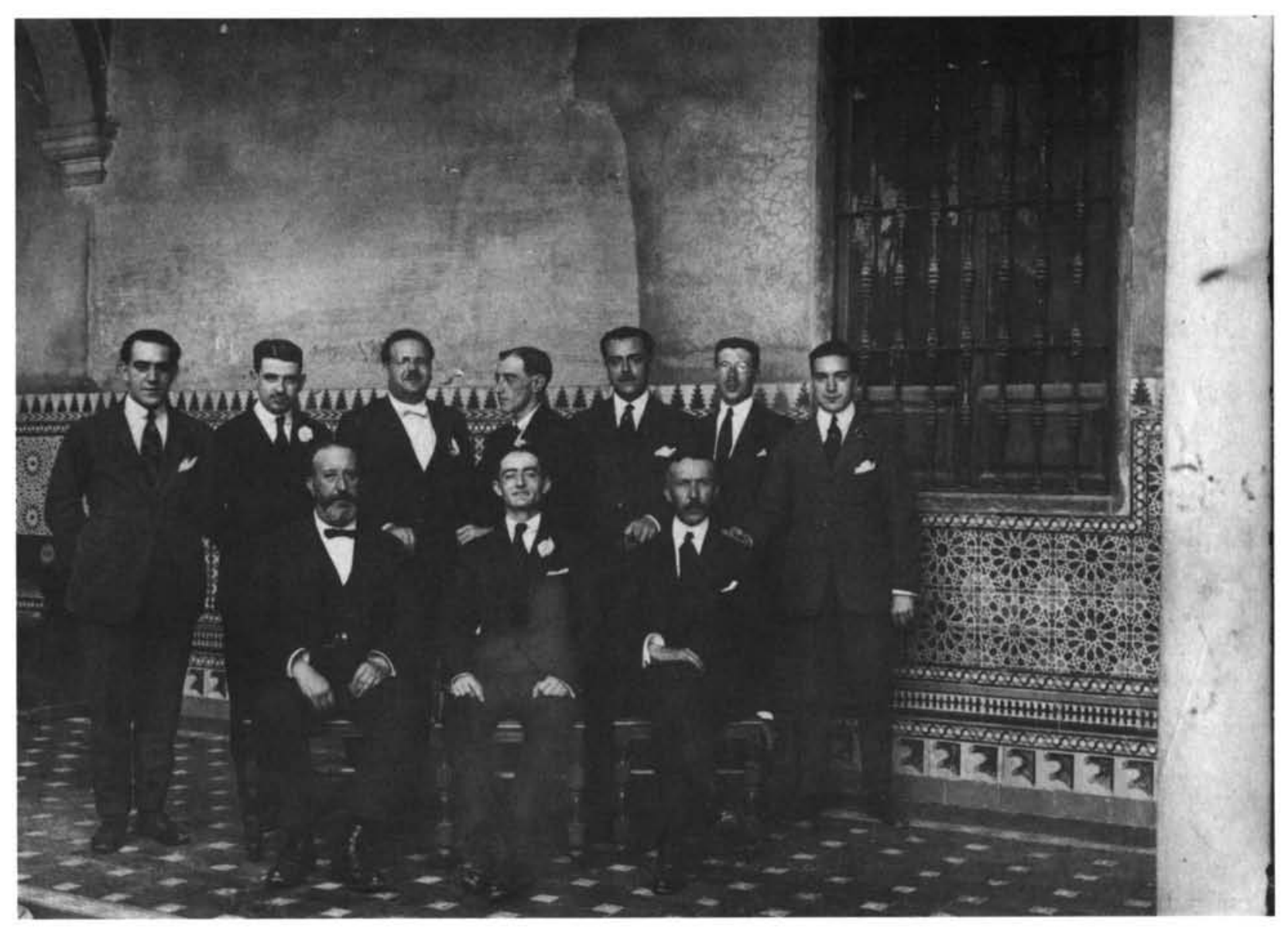




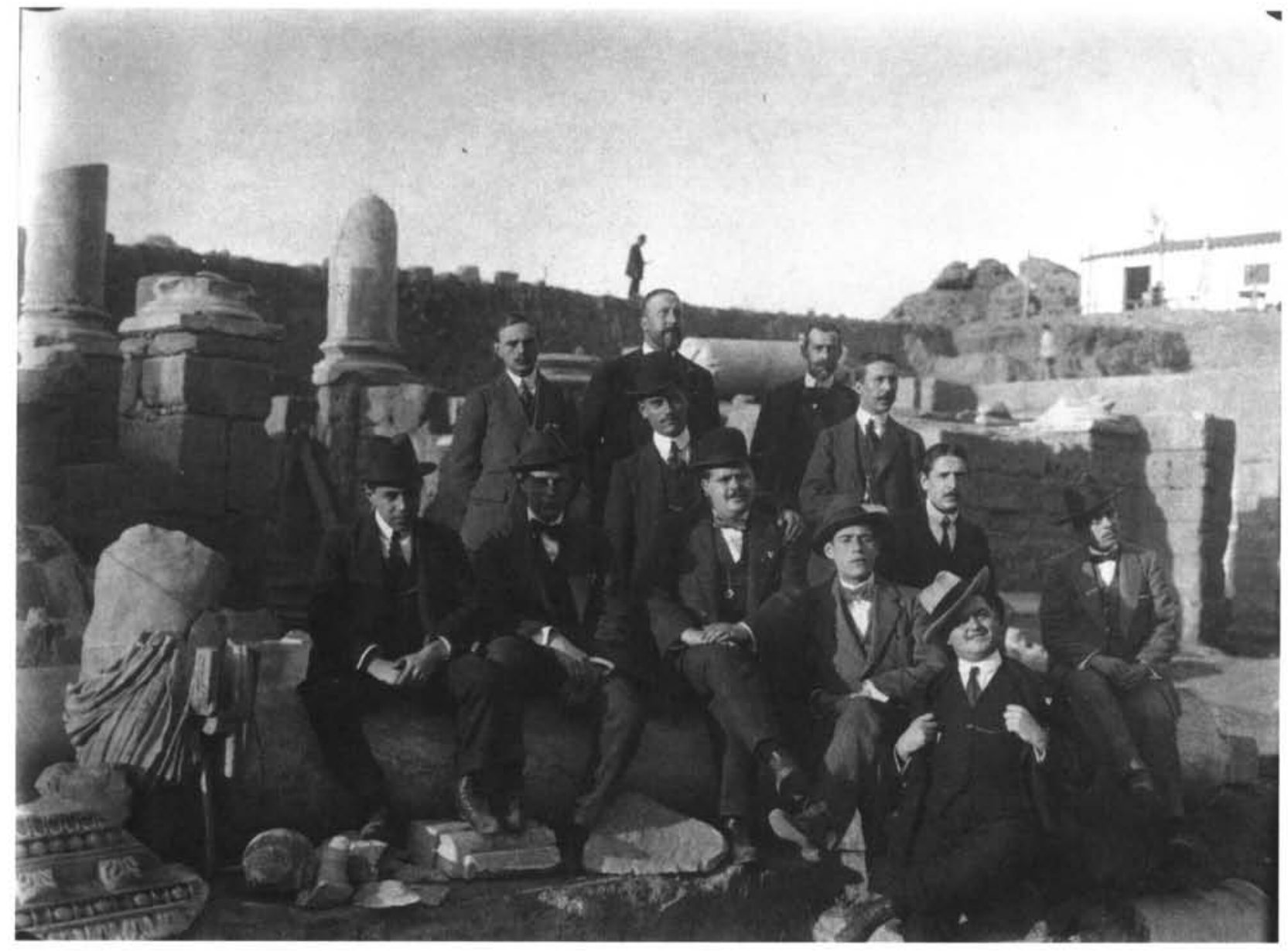

Fotografía 2

Teatro Romano de Mérida. Excursión del 27 de diciembre de 1915. D. Francisco Murillo con sus colaboradores. 